\section{A 15-year-old girl with cramping movements}

\author{
Amanda Spadafora, ${ }^{1,2}$ \\ Andrea Andrade, ${ }^{1,2}$ \\ Rodrick Rodrick Lim ${ }^{1,2}$ \\ 'Departments of Paediatrics and \\ Medicine, Schulich School of Medicine, \\ University of Western Ontario; \\ ${ }^{2}$ Children's Health Research Institute, \\ Children's Hospital, London Health \\ Sciences Centre, London, Ontario, \\ Canada
}

\section{Clinical introduction}

A 15-year old, previously healthy female presented to the emergency department with two weeks of mild crampy abdominal pain lasting approximately 10 15 seconds associated with abdominal wall movements which were visible to both the patient and her mother. There is no correlation of the pain with eating, drinking, bowel movements or her menses, and no aggravating or relieving factors. Interestingly, she has experienced similar symptoms around 2 years ago, and that it resolved spontaneously after a few weeks. Her past medical and family history was unremarkable. A video of these episodes was captured (Video 1).

\section{Question}

What is the most likely diagnosis?
A. Hypercalcemia
B. Periodic paralysis
C. Abdominal wall tic
D. Belly dancer's dyskinesia
E. Psychogenic movement disorder

\section{Answer}

The video (Video 1) and clinical history are most suggestive of an abdominal wall tic. On further questioning, the patient revealed that she was able to suppress the movements for a short time, before the sensation built up and started becoming uncomfortable. This was consistent with the classic feeling of inner tension with tic suppression associated with the premonitory urge preceding the tic. This made the diagnosis of Belly dancer's dyskinesia unlikely given the ability to suppress it without holding her breath. Once the patient was informed, her mother remembered that she too had experienced a tic previously (head turning), which would occur during times of stress.

A tic is defined as being a sudden, repetitive movement or sound, which is often a piece of a normal movement performed outside of the normal situation/context. Tics are unique from other movement disorders in that the patient is able to suppress the movements, however often only for a limited period of time, and are common (5\% of children).

Recognition of unusual tics such as abdominal wall tics in children is important to avoid unnecessary investigations and treatment. As always, clinicians should balance the age and characteristics of the patient, any past history consistent with tics (sniffing, blinking, vocal, etc.), and pertinent physical exams to guide the need for investigations. ${ }^{1-3}$
Correspondence: Rodrick Lim, Children's Hospital at London Health Sciences Centre, 800 Commissioners Road East, London, ON, N6C 2V5, Canada.

Tel: 519-685-8134 - Fax: 519-667-6769.

E-mail: Rod.Lim@lhsc.on.ca

Key words: Cramping movements; Abdominal wall tic; Tic disorders; Children; Adolescents.

Received for publication: 26 July 2017. Revision received: 29 August 2017.

Accepted for publication: 30 August 2017.

This work is licensed under a Creative Commons Attribution 4.0 License (by-nc 4.0).

C Copyright A. Spadafora et al., 2017

Licensee PAGEPress, Italy

Emergency Care Journal 2017; 13:6957

doi:10.4081/ecj.2017.6957

\section{References}

1. Black KJ, Black ER, Greene DJ, Schlaggar BL. Provisional tic disorder: what to tell parents when their child first starts ticcing. F1000 Research 2016;5:696.

2. Mack KJ. Tic disorders and their differential diagnosis in childhood. Pediatr Child Health 2009; 19:235-8.

3. Shin ZH, Jung CH, Kim HC. Follow-up study of the tic disorders. J Korean Acad Child Adolesc Psych 1996;7:6876. 